\title{
The Relationship Between Mid-Ocean Spreading Zone Seismic Activity and Global Temperatures Remains Strong Through 2018
}

\author{
Arthur Viterito* \\ College of Southern Maryland, USA
}

Submission: July 01, 2019; Published: July 16, 2019

*Corresponding author: Arthur Viterito, College of Southern Maryland (retired), La Plata, MD 20646, USA

Abstract

In this short communication, the relationship between mid-ocean seismic activity and global temperatures is extended through 2018 . As in previous studies, the relationship remains strong and is statistically significant. Regional disparities in mid-ocean seismic activity are emerging and will be monitored going forward.

Keywords: Mid-ocean seismic activity; Global temperatures; Regional seismic disparities

\section{Introduction}

The papers titled The Correlation of Seismic Activityand Recent Global Warming (CSARGW), The Correlation of Seismic Activity and Recent Global Warming: 2016 Update (CSARGW16), and Have Global Temperatures Reached a Tipping Point? (HGTRTP) [1-3] document the link between mid-ocean spreading zone seismic activity (MOSZSA) [4] and global temperatures (GT) [5] over the past 40 years. In this brief note, the MOSZSA, as measured by the moment-magnitude 4-6 earthquake frequencies in these high geothermal flux areas, along with GT, are extended through 2018 (Figure 1) to re-test the hypothesis that MOSZSA serves as a significant driver of GT. The methods employed are the same as those detailed in CSARGW with one exception: the data from University of Alabama - Huntsville, version 6.0, are now averaged with the Remote Sensing Systems (RSS) version 4.0 data instead of the older RSS 3.3 version.

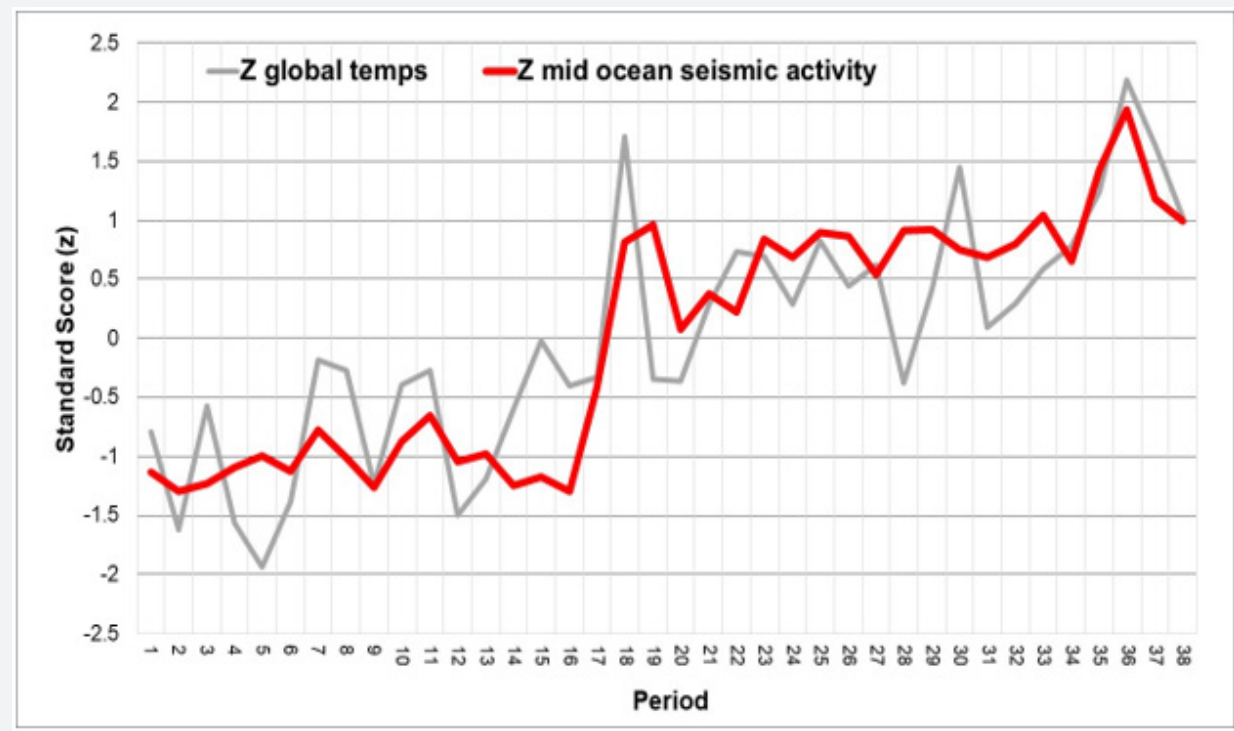

Figure 1: Time series plot of the standard scores for global MOSZSA (red) and GT (gray) from 1979 through 2018. As per the methods outlined in CSARGW, GT is lagged 2 years relative to MOSZSA so that "Period 1" is the 1979 MOSZSA paired with the 1981 GT, "Period 2" is the 1980 MOSZSA paired with the 1982 GT, and so forth. 
As Figure 1 clearly demonstrates, GT remain strongly tied to global MOSZSA through 2018, yielding a correlation coefficient of $0.83(\mathrm{P}<0.001)$. As detailed in CSARGW, the high correlation can be explained by the fact that greater MOSZSA is a proxy for intensified geothermal flux (GF) in these areas [6]. Greater GF strengthens the thermohaline circulation, facilitating greater heat flux into the North Atlantic and the Arctic [7-10]. Warmer bottom water also intensifies thermobaric convection in Polar regions, a ventilating mechanism that promotes greater vertical heat transport throughout the water column $[11,12]$. Consistent with the outcomes generated in CSARGW, CSARGW16, and HGTRTP, multiple regression determines that MOSZSA frequencies are significant $(\mathrm{P}<0.02)$ while atmospheric $\mathrm{CO}_{2}$ concentrations are not $(\mathrm{P}>0.1)$.

The global MOSZSA through May 2019 is depicted in Figure 2 , and it appears that a new basing pattern might be emerging. The activity for the past 29 months has yielded an average of 439 events per year. By contrast, the 21-year period from 1996 to 2016, a period referred to as "The Pause", averaged 607 events per year. This difference is statistically significant $(\mathrm{p}<.001)$ and represents a distinct break from the previous two decades. If the MOSZSA/GT hypothesis is correct and the regression parameters have predictive value, we can expect GT to gap downward.

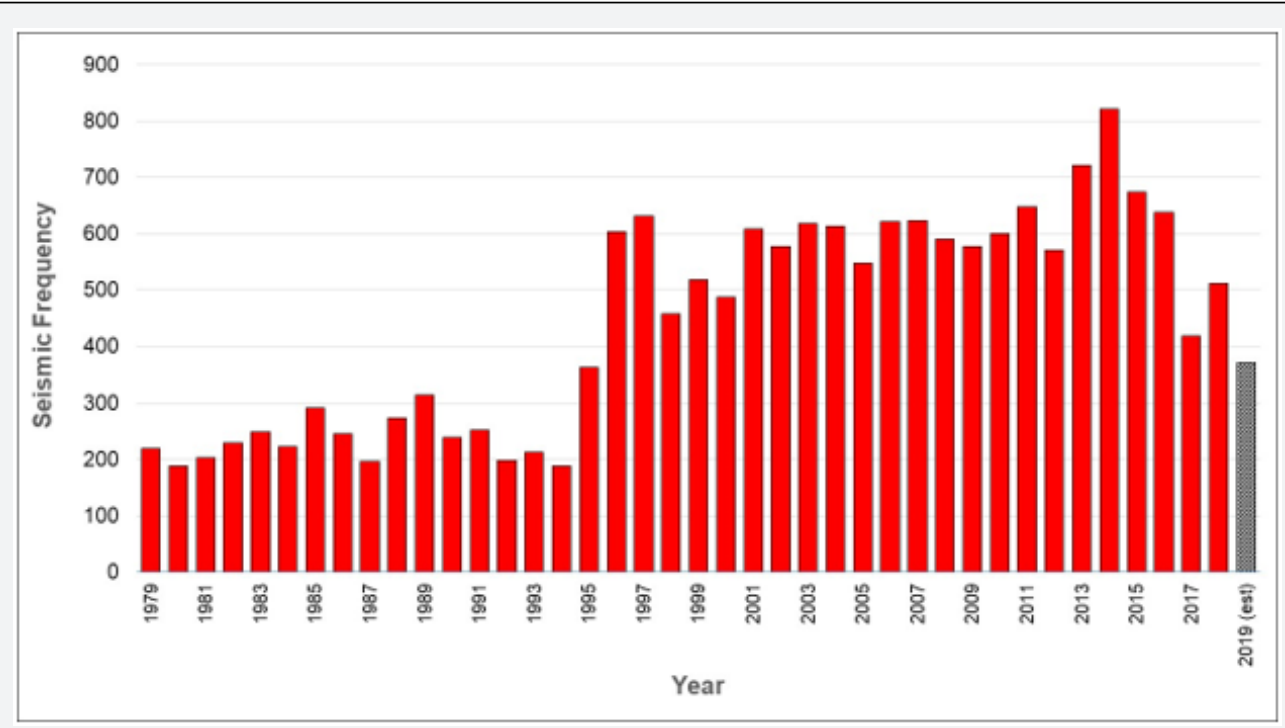

Figure 2: Global MOSZSA, moment-magnitude 4 - 6 frequencies through May 31, 2019.

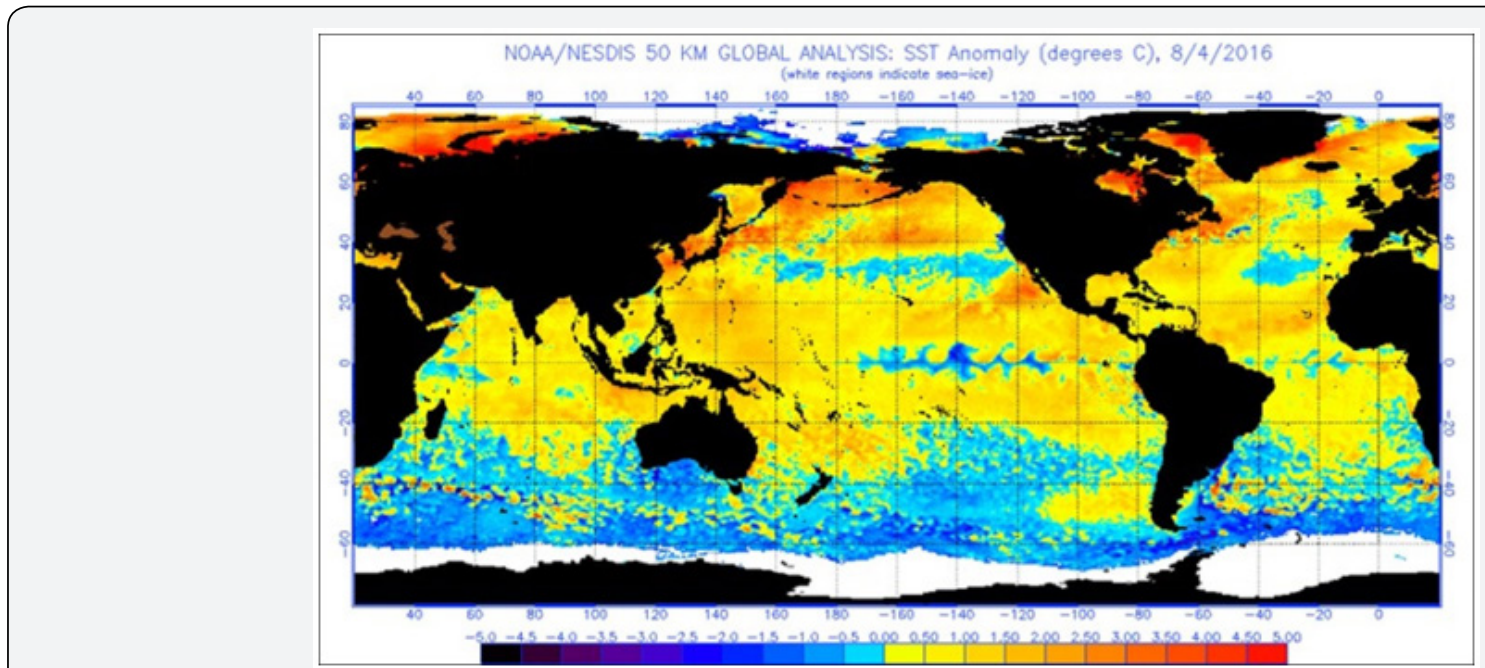

Figure 3: Sea-surface temperature anomalies, 8/4/2016.

The pattern of sea surface temperatures (SST) reflects conditions that support the MOSZSA/GT hypothesis. As Figure 3 shows [13], the 2016 "Super El Niño" was accompanied by very high SST in the North Pacific, North Atlantic, and the Arctic Ocean (i.e., the pattern that comports with the "Arctic Amplification"). The very high MOSZSA (the highest level recorded for the 40year study period) two years prior supports the argument that the high latitude amplification was driven by enhanced GF and 
probably not by other drivers commonly cited in the literature (i.e., radiative forcing by increasing $\mathrm{CO}_{2}$, changing solar output, and/or changing cloud cover). By comparison, the current
SST pattern (Figure 4) is a sharp contrast to this and may be indicative of a weakening thermohaline circulation, as signaled by the significantly lower SST in the northern oceans [14].

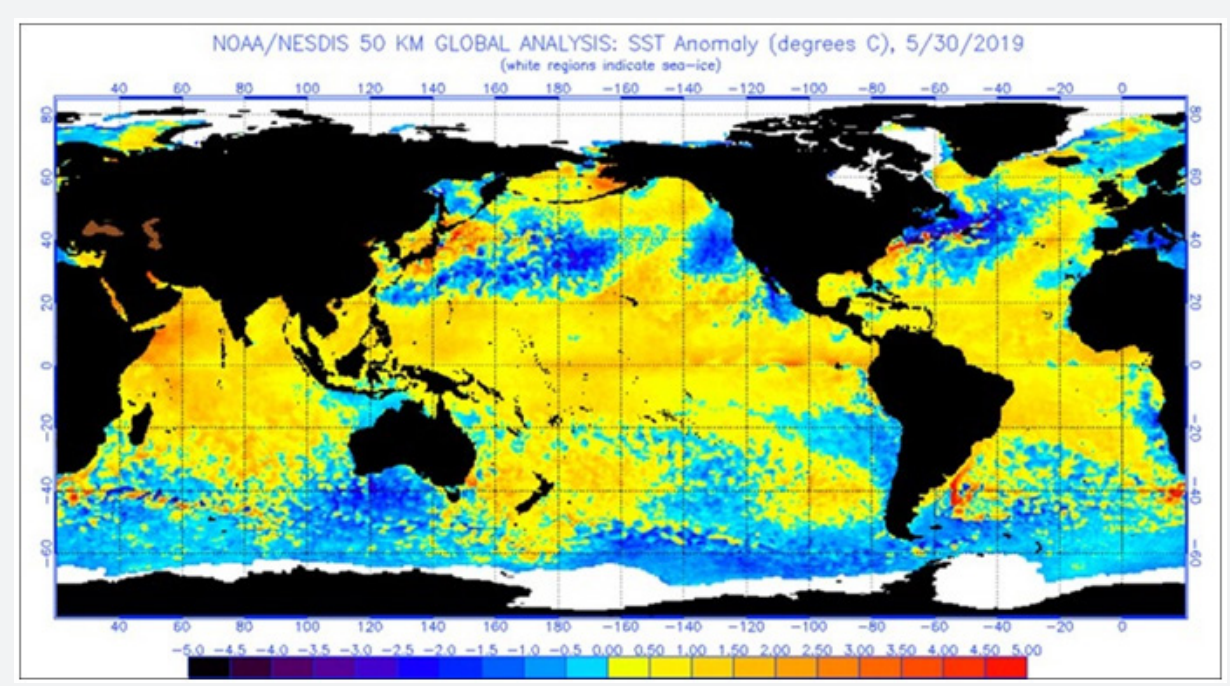

Figure 4: Sea-surface temperature anomalies, 5/30/2019.

Another significant trend is the emergence of regional disparities in MOSZSA. In accordance with the regional delineations detailed in CSARGW, MOSZSA statistics are compiled for the Indian, Atlantic and Pacific Oceans (Figure 5-7). In lockstep with the global drop-off in MOSZSA, all regional frequencies began to trend downward in 2014 and 2015. As Figure 5 shows, the declines in the Indian Ocean have been the sharpest while more muted declines are developing in the Atlantic and the Pacific (Figure $6 \& 7$ ). At present, the seismic frequencies for all three oceans are comparable to those of the mid-1990s, and it has yet to be determined if these levels will continue to decline, reverse course, or plateau. It should also be noted that a number of studies have documented bottom warming in the Southern (i.e., the southern reaches of the Atlantic, Indian and Pacific), Arctic, and North Pacific Oceans beginning in the mid1990s. While GF was cited as the primary forcing agent in the Arctic Ocean [11], it was not considered a factor for the Southern or North Pacific Oceans $[15,16]$. More importantly, the drivers of MOSZSA are poorly understood at this time and it is not possible to predict future MOSZSA trends on any spatial scale.

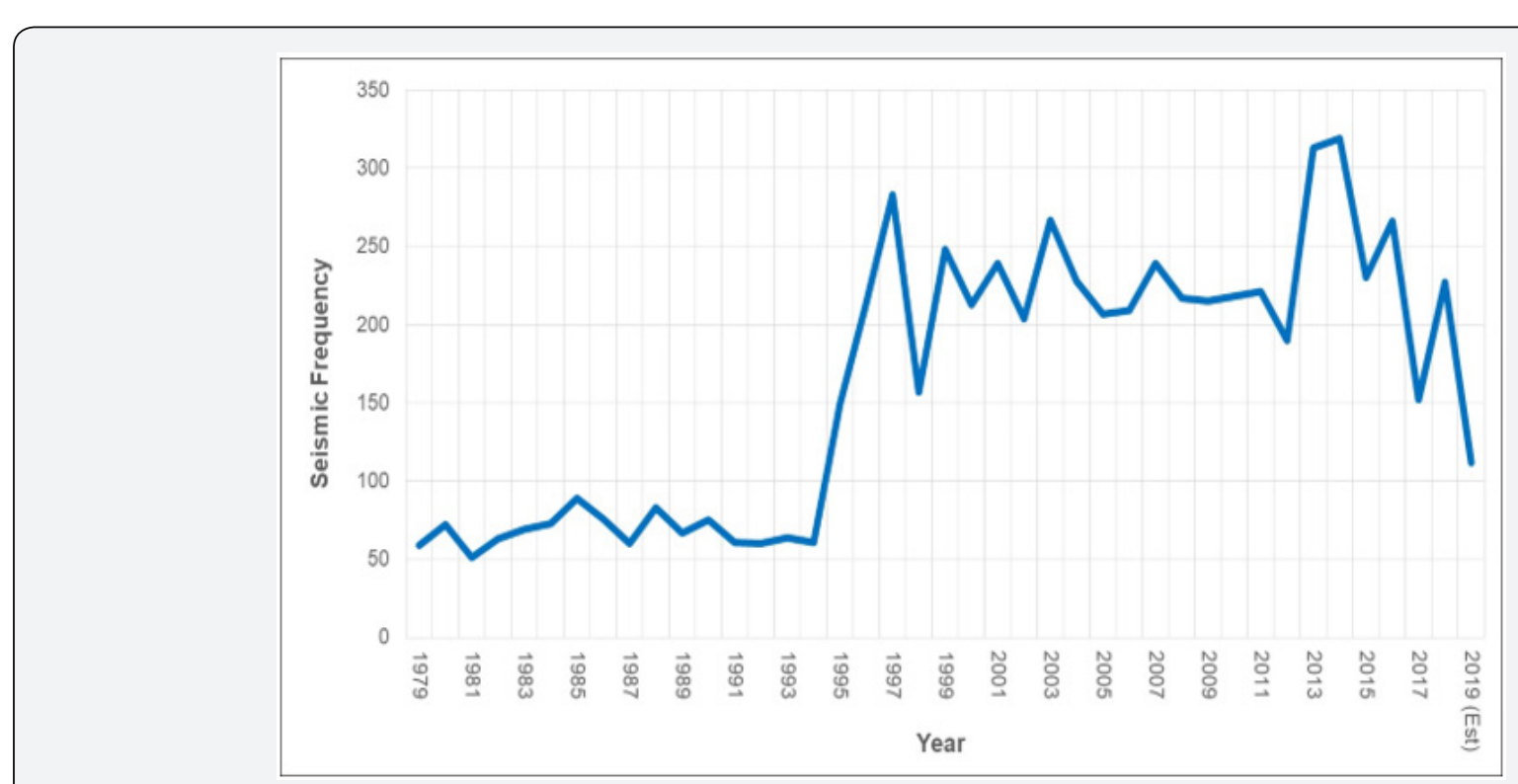

Figure 5: MOSZSA for the Indian Ocean, moment-magnitude 4 - 6 frequencies through May 31, 2019. 


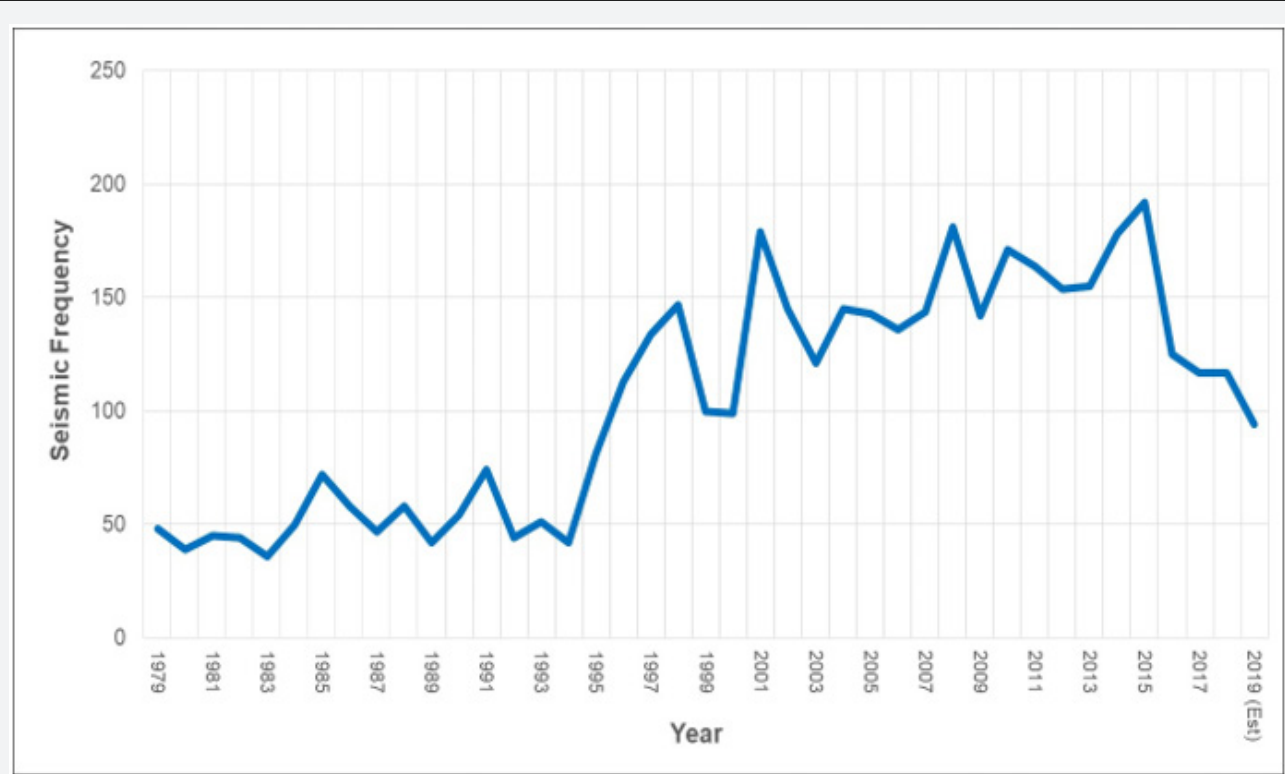

Figure 6: MOSZSA for the Pacific Ocean, moment-magnitude 4 - 6 frequencies through May 31, 2019.

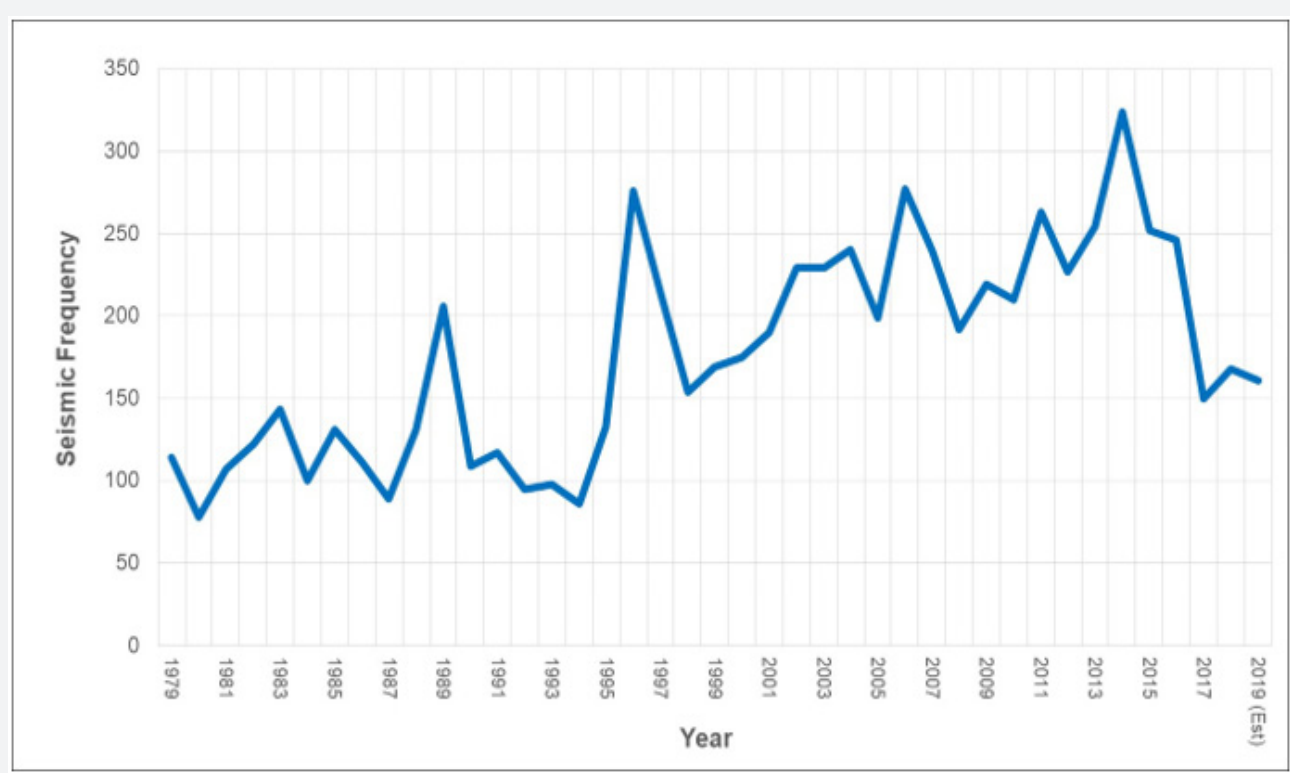

Figure 7: MOSZSA for the Atlantic Ocean, moment-magnitude 4 - 6 frequencies through May 31, 2019.

\section{Conclusion}

The correlation of MOSZSA and GT showed continued strength through 2018. As per the practice in previous years, a follow-up research note will be drafted after GT and MOSZSA data have been compiled for all of 2019. It is anticipated that continued exploration of these datasets will further validate the hypothesis that MOSZSA and GT are linked in a meaningful way while rendering a clearer picture of emerging global and regional trends. In addition, links to other potential drivers may be better understood and assessed. Of course, the ultimate goal of these efforts is to develop the skills needed to accurately forecast GT from MOSZSA and other significant drivers.

\section{References}

1. Viterito A (2016) The correlation of seismic activity and recent global warming. Journal of Earth Science and Climate Change 7: 345.

2. Viterito A (2017) The correlation of seismic activity and recent global warming: 2016 Update. Environment Pollution and Climate Change 1: e103.

3. Viterito A (2018) Have global temperatures reached a tipping point? Environment Pollution and Climate Change 2(1): 149.

4. http://ds.iris.edu/wilber3/find_event

5. https://www.ncdc.noaa.gov/temp-and-precip/msu/

6. Davis E, Becker K, Dziak R, Cassidy J, Wang K, et al. (2004) Hydrological response to a seafloor spreading episode on the Juan de Fuca Ridge. Nature 430(6997): 335-338. 
7. Ballarotta M, Roquet F, Falahat S, Zhang Q, Madec G (2015) Impact of the oceanic geothermal heat flux on a glacial ocean state. Climates of the Past Discussions 11: 3597-3624.

8. Scott JR, Martozke J, Adcroft A (2001) Geothermal heating and its influence on the meridional overturning circulation. Journal Geophysical Research 106(C12): 31141-31154.

9. Mullarney JC, Griffiths RW, Hughes GO (2006) The effects of geothermal heating on the ocean overturning circulation. Geophysical Research Letters 33(2): L02607.

10. Urakawa LS, Hasumi H (2009) A remote effect of geothermal heat on the global thermohaline circulation. Journal of Geophysical Research 114(C7): C07016.

11. Carmack EC, Williams WJ, Zimmermann SL, McLaughlin FA (2012) The Arctic Ocean warms from below. Geophysical Research Letters 39: L07604.

This work is licensed under Creative Commons Attribution 4.0 License

DOI: 10.19080/IJESNR.2019.20.556039
12. Akitomo K, Awaji T, Imasato N (1995) Open-ocean deep convection in the Weddell Sea: Two-dimensional numerical experiments with a nonhydrostatic model. Deep Sea Research Part 1: Oceanographic Research Papers 42(1): 53-73.

13.https: / /www.ospo.noaa.gov/data/s st/anomaly/2016/ anomnight.8.4.2016.gif

14.https: / /www.ospo.noaa.gov/data/s st/anomaly/2019/ anomnight.5.30.2019.gif

15. Purkey SG, Johnson GC (2010) Warming of Global Abyssal and Deep Southern Ocean waters between the 1990s and 2000s: Contributions to global heat and sea level rise budgets. Journal of Climate 23: 63366351.

16. Fukasawa M, Freeland H, Perkin R, Watanabe T, Uchida H, et al. (2004) Bottom water warming in the North Pacific Ocean. Nature 427(6977): 825-827.

Your next submission with Juniper Publishers will reach you the below assets

- Quality Editorial service

- Swift Peer Review

- Reprints availability

- E-prints Service

- Manuscript Podcast for convenient understanding

- Global attainment for your research

- Manuscript accessibility in different formats (Pdf, E-pub, Full Text, Audio)

- Unceasing customer service

Track the below URL for one-step submission https://juniperpublishers.com/online-submission.php 